\title{
Varẻnos šnektos daiktavardžio morfologinio proceso (fleksinių formų) natūralumas
}

\author{
VITALIJA KARACIEJŪTÉ \\ Lietuvos edukologijos universitetas, T. Ševčenkos $g$. 31, LT-03111 Vilnius \\ El. paštas: vitalija.karaciejute@leu.lt
}

\begin{abstract}
Varènõs šnektos daiktavardžio morfologinio proceso (fleksinių formų) natūralumas iki šiol nèra tirtas ir aprašytas. Straipsnio tikslas - nustatyti šios šnektos daiktavardžių viso morfologinio proceso (fleksinių formų) skaidrumą; remiantis natūraliosios morfologijos teorijos principais, ịvertinti ir aprašyti konstrukcinị linksnių formų ikoniškumą, daiktavardžio formų (vertikalųji) ir galūnių (horizontalųji) sinkretizmą. Varénos šnektos fleksinių formų analizè parodè, kad ne visas morfologinis procesas (fleksinès formos) yra skaidrus - šnektoje esama neikoniškų ir sinkretinių formų, todèl netikslu būtų šnektos fleksinę sistemą laikyti idealiai natūralia.
\end{abstract}

Raktažodžiai: Varẻnos šnekta, natūralioji morfologija, konstrukcinis linksnių formų ikoniškumas, vertikalusis (formų) sinkretizmas, horizontalusis (galūnių) sinkretizmas

\section{IVADAS}

Natūralumo teoriją sudaro universalaus žymètumo teorija (angl. universal markedness theory), tipologinio adekvatumo teorija (1) (angl. theory of typological adequacy) ir konkrečios kalbos sistemos adekvatumo teorija (angl. theory of language-specific system adequacy) [3, 23]. Nors, W. Dresslerio [3, 23] teigimu, sistemos adekvatumas susijęs su daugeliu sutartinių, arba pasirinktinų, elementų, tačiau kartu jis yra reguliuojamas visuotinių principų, vienas iš jų - paradigmos struktūros sąlyga, pasiūlyta W. U. Wurzelio (1984 (2)).

Teorine ir parametrizuota universalaus žymėtumo teorijos sąvoka žymétumas (angl. markedness) grindžiama ekstralingvistinèmis ir semiotinėmis idejomis ir siejama su tuo, kas yra paprasta, kognityviai labiau prieinama, veiksminga, t. y. produktyvu bendravimo procese $[4,290]$. Taigi čia svarbu minèti iš semiotikos kilusị ikoniškumo (3)

(1) Dar žr. [4, 293].

(2) Wurzel, W. U. Flexionsmorphologie und Natürlichkeit (Studia Grammatica, XXI). Berlin, 1984.

(3) Apie ikonas (ženklus) ir ikoniškumą plačiau žr. [15, 47-72]. 
(angl. iconicity) parametrą ir jo konstrukcinio ikoniškumo (angl. constructional iconicity) subparametrą $[4,290]$.

Morfologinis procesas bus maksimaliai natūralus, jeigu jis „atitiks savo ikonišką funkcinị potencialą" (4), kitaip tariant, jeigu bus sudaryta galimybè, arba sąlyga, konstrukciškai ikoniškam produktyvumui. Vadinasi, morfologinis procesas turi būti adityvinis (angl. additive), o ne subtrakcinis (angl. subtraction) ar modifikacinis (5) (angl. modify, conversion) [1, 58-59] (6). Taigi L. Bauerio aptartas morfologinis procesas siejamas su W. U. Wurzelio aprašytomis tam tikromis morfologinemis operacijomis, arba kaitybos taisyklemis, kurios lemia morfologinių kategorijų formalų simbolizavimą žodyje ir kuriomis sukuriamos fleksinès (kaitybinès) formos, savo fonologine substancija kiekybiškai ir (arba) kokybiškai besiskiriančios nuo žodžių pamatinių formų [18, 42; 14, 35].

Pietų aukštaičių patarmei priskiriamos Varẻnõs šnektos daiktavardžio morfologinio proceso (fleksinių formų) natūralumas iki šiol nebuvo tirtas ir aprašytas, todèl tyrimu siekiama nustatyti šios šnektos daiktavardžių viso morfologinio proceso (fleksinių formų) skaidrumą. Keliama prielaida, kad tiriamosios šnektos fleksinè sistema nèra idealiai natūrali. Remiantis natūraliosios morfologijos teorijos, kuri susiformavo susiejus žymètumo ir fonologinio natūralumo sąvokas [4, 289], principais (7), siekiama ịvertinti ir aprašyti konstrukcinị linksnių formų ikoniškumą, daiktavardžio formų (vertikalųjį) ir galūnių (horizontalųjį) sinkretizmą.

Empirinę tyrimo medžiagą sudaro straipsnio autorès 2005-2013 metais individualiai sukaupti šnektos tekstai iš Varènos ir arčiausiai jos esančių kaimų - Akmeñs, Babriškių, Bar̃čių, Beržùpio, Giráitès, Kašẽtų, Mer̃gežerio, Matùizų, Perlojõs, Pauosupẽs, Rùdnios, Senõsios Varènõs, Ūtõs, Zervýnų, Žiūrų. Analizuoti pasirinkta vyresnès kartos atstovų (8), gimusių 1913-1939 m. ir nuolat gyvenančių tiriamosios šnektos plote, kalba. Tiriant Varènos šnektos fleksinès sistemos natūralumą, naudotasi deskripciniu, opozicijų ir distribuciniu metodais.

\section{KONSTRUKCINIS LINKSNIŲ FORMŲ IKONIŠKUMAS}

Varènos šnektos daiktavardžiai kaitomi prie pamatinės formos kamieno pridedant vis kitą, skirtingą, o ne papildomą, gramatinę morfemą [plg. 14, 35]. Ir, nors morfologinis procesas maksimaliai natūralus yra tada, kai optimaliai koduojamas specifinèje kategorijoje [1, 59], adityvinès (9) taisyklès (darant išvestines formas) gali būti derinamos su modifikacinèmis (10) ir net subtrakcinėmis (11) taisyklèmis $[18,43 ; 14,36]$. Taisyklès egzistuoja ten, kur

(4) "A morphological process is maximally natural if it applies within its iconic function-potential and if it is optimally coded in a category-specific way" $[1,58]$.

(5) Dèl terminų modifikacinis ir moduliacinis žr. [14, 36; 2 išnaša].

(6) Čia ir kitur autorius remiasi W. Mayerthaleriu (1981).

(7) Plačiau apie šią teoriją žr. $[7 ; 11 ; 18]$.

(8) Informantai, gimę XX amžiaus 2-4 deš. ( 70 ir daugiau metų), darbe sąlygiškai vadinami vyresniąja karta; plg. [5, 6; 16, 17-18].

(9) Adityvinis, arba segmentinis adityvinis, išvestinių formų tipas turimas tada, kai išvestinių formų gramatinè morfema išlaiko pamatinès formos segmentinị elementą, prie kurio pridedamas koks nors kokybiškai skirtingas elementas [18, 43]; plačiau žr. [14, 36-37].

(10) Modifikacinis išvestinių formų tipas turimas tada, kai išvestinès formos gramatinė morfema nuo pamatinès formos gramatinès morfemos skiriasi ne segmentų skaičiumi, o kokybe arba kai jų gramatinès morfemos turi vienodą segmentų skaičių ir skiriasi baigiamaisiais segmentais [18, 43]; plačiau žr. [14, 37-38].

(11) Subtrakciniam išvestinių formų tipui priklauso tokios išvestinės formos, kurių gramatinės morfemos turi mažiau segmentų už pamatinès formos gramatinę morfemą [18, 43-44]; plačiau žr. [14, 38]. 
fleksinės formos kiekybiškai ir (arba) kokybiškai skiriasi nuo žodžių pamatinių formų, tačiau yra išvestinių formų, kurioms būdingos nulinès taisyklès (angl. zero rules) [18, 42, 50] (12).

Fleksinių formų kodavimas remiasi penkiais konstrukcinio ikoniškumo laipsniais; konstrukcinis ikonizmas „,išryškèja tada, kai dviejų kategorijų asimetrija semantinio žymètumo atžvilgiu atsispindi jų simbolizavimo asimetrijoje“ [18 (13), 50-51; plg.: 11, 18; 14, 39].

Fleksinių formų kodavimas gali būti maksimaliai ikoniškas (max sim) (asimetrija realizuojama adityviškai), mažiau negu maksimaliai ikoniškas (sim) (asimetrija realizuojama modifikuotu adityviniu būdu), minimaliai ikoniškas (min ik.) (asimetrija realizuojama modifikuotai), neikoniškas (-ik.) (semantinio žymètumo asimetrija neatsispindi simbolizavimo asimetrijoje; neikoniškos yra nekintamojo tipo formos), kontraikoniškas (kontrik.) (semantinio žymėtumo asimetrija atsispindi inversinëje simbolizavimo asimetrijoje; kontraikoniškos yra subtrakcinio tipo formos) $[14,39]$.

Toliau pateikiami Varẻnos šnektos visų kamienų daiktavardžių išvestinių formų tipai ir ikoniškumo laipsniai (žr. 1 lentelę).

1 lentelè. Varẻnos šnektos daiktavardžių išvestinių formų tipai ir ikoniškumo laipsniai (14)

\begin{tabular}{|c|c|c|c|}
\hline \multicolumn{4}{|c|}{ Vyriškasis linksniavimas ( $a, i a_{1}, i a_{2}, u, i u$ kamienai) } \\
\hline Linksnis & Fleksinè forma & Formos tipas & Ikoniškumo laipsnis \\
\hline \multicolumn{4}{|c|}{ Pamatinè forma $d \alpha \tilde{r} \check{z}-a s, k \dddot{x} . l-e s$} \\
\hline \multirow{2}{*}{ Vns. kilm. } & $d \alpha \tilde{r} \check{z}-o$. & subtrakcinis & kontraikoniška \\
\hline & kǽ. $\hat{l}-o$. & subtrakcinis & kontraikoniška \\
\hline \multirow{2}{*}{ Vns. naud. } & $d \alpha \tilde{r} \check{z}-u$ & subtrakcinis & kontraikoniška \\
\hline & kǽ. $\hat{l}-u$ & subtrakcinis & kontraikoniška \\
\hline \multirow{2}{*}{ Vns. gal. } & $d \alpha \tilde{r} \check{z}-u$. & subtrakcinis & kontraikoniška \\
\hline & kǽ. & subtrakcinis & kontraikoniška \\
\hline \multirow{2}{*}{ Vns. įng. } & $d \alpha r \check{z}-\grave{u}$ & subtrakcinis & kontraikoniška \\
\hline & $k e \hat{l}-\grave{u}$ & subtrakcinis & kontraikoniška \\
\hline \multirow{2}{*}{ Vns. viet. } & $d \alpha r \check{z}-\grave{i}$ & subtrakcinis & kontraikoniška \\
\hline & $k e l-\tilde{i}$ & subtrakcinis & kontraikoniška \\
\hline \multirow{2}{*}{ Vns. iliat. } & $d \alpha r \check{z}-\alpha \tilde{n}$ & modifikacinis & minimaliai ikoniška \\
\hline & kel-eñ & modifikacinis & minimaliai ikoniška \\
\hline \multirow{2}{*}{ Dgs. vard. } & $d \alpha r z ̌-\alpha \tilde{i}$ & modifikacinis & minimaliai ikoniška \\
\hline & $k e l-e \tilde{i}$ & modifikacinis & minimaliai ikoniška \\
\hline \multirow{2}{*}{ Dgs. kilm. } & $d \alpha r \check{z}-\tilde{u}$ & subtrakcinis & kontraikoniška \\
\hline & $k e \hat{l}-\tilde{u}$ & subtrakcinis & kontraikoniška \\
\hline \multirow{2}{*}{ Dgs. naud. } & $d \alpha r z ̌-a ́ m$ & modifikacinis & minimaliai ikoniška \\
\hline & kel-ǽ’m & modifikacinis & minimaliai ikoniška \\
\hline
\end{tabular}

(12) Nekintamasis (angl. unchanged) išvestinių formų tipas, kai išvestinès ir pamatinès formų gramatinès morfemos nesiskiria nei savo ilgumu, nei struktūra [18, 49-50; 14, 38].

(13) Atkreiptinas dèmesys ị tai, kad W. U. Wurzelis [18, 50-51], aptardamas ikoniškumo laipsnius, nemini mažiau negu maksimaliai ikoniško (sim) fleksinių formų kodavimo.

(14) Remiamasi oksitoninio kirčiavimo daiktavardžiais, kad būtų geriau atstovaujama visoms fleksinėms klasèms. 


\begin{tabular}{|c|c|c|c|}
\hline \multicolumn{4}{|l|}{1 lentelès tęsinys } \\
\hline \multicolumn{4}{|c|}{ Vyriškasis linksniavimas ( $a, i a_{1}, i a_{2}, u, i u$ kamienai) } \\
\hline Linksnis & Fleksinė forma & Formos tipas & Ikoniškumo laipsnis \\
\hline \multirow{2}{*}{ Dgs. gal. } & 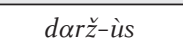 & modifikacinis & minimaliai ikoniška \\
\hline & kêे-ùs & modifikacinis & minimaliai ikoniška \\
\hline \multirow{2}{*}{ Dgs. įng. } & $d \alpha r \check{z}-\alpha \tilde{i} s$ & adityvinis & maksimaliai ikoniška \\
\hline & kel-eîs & adityvinis & maksimaliai ikoniška \\
\hline \multirow{2}{*}{ Dgs. viet. } & dorž-úosa & adityvinis & maksimaliai ikoniška \\
\hline & $k e \hat{l}-u ́ o s a$ & adityvinis & maksimaliai ikoniška \\
\hline \multirow{2}{*}{ Dgs. iliat. } & d $\alpha r \check{z}-u \tilde{s} n a$ & adityvinis & maksimaliai ikoniška \\
\hline & kêे-uõsna & adityvinis & maksimaliai ikoniška \\
\hline \multicolumn{4}{|c|}{ Pamatinè forma gro.v-ĩis, su'n-ùs, ŝpieĉ-ùs (15) } \\
\hline \multirow{3}{*}{ Vns. kilm. } & grỗv-o. & subtrakcinis & kontraikoniška \\
\hline & su.n-åús & adityvinis & maksimaliai ikoniška \\
\hline & ŝpiec-åũs & adityvinis & maksimaliai ikoniška \\
\hline \multirow{3}{*}{ Vns. naud. } & gr̂̃öv-u & subtrakcinis & kontraikoniška \\
\hline & sún-u & subtrakcinis & kontraikoniška \\
\hline & 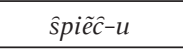 & subtrakcinis & kontraikoniška \\
\hline \multirow{3}{*}{ Vns. gal. } & gr̂̃öv-i. & subtrakcinis & kontraikoniška \\
\hline & sún-u. & subtrakcinis & kontraikoniška \\
\hline & $\hat{s p i e ̂ \hat{c}-u .}$ & subtrakcinis & kontraikoniška \\
\hline \multirow{3}{*}{ Vns. ing. } & gr̂o.v-ù & subtrakcinis & kontraikoniška \\
\hline & 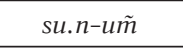 & modifikacinis & minimaliai ikoniška \\
\hline & 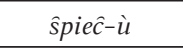 & subtrakcinis & kontraikoniška \\
\hline \multirow{3}{*}{ Vns. viet. } & 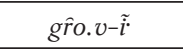 & subtrakcinis & kontraikoniška \\
\hline & $d \alpha n g-\grave{u} i$ & modifikacinis & minimaliai ikoniška \\
\hline & spiêç-ui & modifikacinis & minimaliai ikoniška \\
\hline \multirow{3}{*}{ Vns. iliat. } & gro.v-iñ & modifikacinis & minimaliai ikoniška \\
\hline & 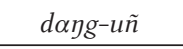 & modifikacinis & minimaliai ikoniška \\
\hline & $\hat{s} p i e \hat{c}-u \tilde{n}$ & modifikacinis & minimaliai ikoniška \\
\hline \multirow{3}{*}{ Dgs. vard. } & gr̂ro.v-eĩ & modifikacinis & minimaliai ikoniška \\
\hline & su.n- $\alpha \tilde{i}$ & modifikacinis & minimaliai ikoniška \\
\hline & spiec-ẹ $\tilde{i}$ & modifikacinis & minimaliai ikoniška \\
\hline \multirow{3}{*}{ Dgs. kilm. } & $g \hat{r} o . \hat{v}-\tilde{u}$ & subtrakcinis & kontraikoniška \\
\hline & su.n- $\tilde{u}$ & subtrakcinis & kontraikoniška \\
\hline & 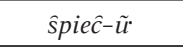 & subtrakcinis & kontraikoniška \\
\hline \multirow{3}{*}{ Dgs. naud. } & gr̂o.v-ǽ’m & modifikacinis & minimaliai ikoniška \\
\hline & su.n-ám & modifikacinis & minimaliai ikoniška \\
\hline & spiec-ǽ’m & modifikacinis & minimaliai ikoniška \\
\hline
\end{tabular}

(15) Varènos šnektoje daiktavardis ŝpieĉùs kirčiuojamas pagal 4 kirčiuotę; plg. [8]. 


\begin{tabular}{|c|c|c|c|}
\hline \multicolumn{4}{|l|}{1 lentelès tęsinys } \\
\hline \multicolumn{4}{|c|}{ Vyriškasis linksniavimas $\left(a, i a_{1}, i a_{2}, u, i u\right.$ kamienai) } \\
\hline Linksnis & Fleksinè forma & Formos tipas & Ikoniškumo laipsnis \\
\hline \multirow{3}{*}{ Dgs. gal. } & gr̂o.v-ùs & modifikacinis & minimaliai ikoniška \\
\hline & sứn-us & nekintamasis & neikoniška \\
\hline & ŝpieĉ-ùs & nekintamasis & neikoniška \\
\hline \multirow{3}{*}{ Dgs. ing. } & gr̂.o.v-eĩs & adityvinis & maksimaliai ikoniška \\
\hline & 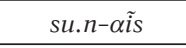 & adityvinis & maksimaliai ikoniška \\
\hline & ŝpiec-ẹis & adityvinis & maksimaliai ikoniška \\
\hline \multirow{3}{*}{ Dgs. viet. } & gr̂o.v̂-úosa & adityvinis & maksimaliai ikoniška \\
\hline & dayg-úosa & adityvinis & maksimaliai ikoniška \\
\hline & spieç-úosa & adityvinis & maksimaliai ikoniška \\
\hline \multirow{3}{*}{ Dgs. iliat. } & gr̂o.v̂-uõsna & adityvinis & maksimaliai ikoniška \\
\hline & dayg-uõsna & adityvinis & maksimaliai ikoniška \\
\hline & ŝpieĉ-uõsna & adityvinis & maksimaliai ikoniška \\
\hline \multicolumn{4}{|c|}{ Moteriškasis linksniavimas ( $\bar{a}, \bar{e}$ kamienai) } \\
\hline \multicolumn{4}{|c|}{ Pamatinè forma kas-à, de. žz- } \\
\hline \multirow{2}{*}{ Vns. kilm. } & kas-õ's & adityvinis & maksimaliai ikoniška \\
\hline & de. $\ddot{z}-\tilde{e} \cdot s$ & adityvinis & maksimaliai ikoniška \\
\hline \multirow{2}{*}{ Vns. naud. } & $k \tilde{a} s-\alpha i$ & adityvinis & maksimaliai ikoniška \\
\hline & $d \tilde{e} \check{z}-e i$ & adityvinis & maksimaliai ikoniška \\
\hline \multirow{2}{*}{ Vns. gal. } & kãs-u. & modifikacinis & minimaliai ikoniška \\
\hline & $d \tilde{e}: \ddot{z}-i$. & modifikacinis & minimaliai ikoniška \\
\hline \multirow{2}{*}{ Vns. ing. } & kas-ù & modifikacinis & minimaliai ikoniška \\
\hline & $d e . \check{z}-\grave{i}$ & modifikacinis & minimaliai ikoniška \\
\hline \multirow{2}{*}{ Vns. viet. } & kas-õori & adityvinis & maksimaliai ikoniška \\
\hline & de..ž- $\tilde{z} \underline{i} i$ & adityvinis & maksimaliai ikoniška \\
\hline \multirow{2}{*}{ Vns. iliat. } & kas-õn & adityvinis & maksimaliai ikoniška \\
\hline & $d e . \check{z}-\tilde{e} n$ & adityvinis & maksimaliai ikoniška \\
\hline \multirow{2}{*}{ Dgs. vard. } & kãs-o.s & adityvinis & maksimaliai ikoniška \\
\hline & $d \tilde{e} \check{z}-e . s$ & adityvinis & maksimaliai ikoniška \\
\hline \multirow{2}{*}{ Dgs. kilm. } & 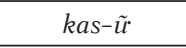 & modifikacinis & minimaliai ikoniška \\
\hline & de. $\tilde{z}-\tilde{u}$ & modifikacinis & minimaliai ikoniška \\
\hline \multirow{2}{*}{ Dgs. naud. } & kas-óm & adityvinis & maksimaliai ikoniška \\
\hline & de..ž- $\tilde{e} m$ & adityvinis & maksimaliai ikoniška \\
\hline \multirow{2}{*}{ Dgs. gal. } & kas-às & adityvinis & maksimaliai ikoniška \\
\hline & de..ž-ès & adityvinis & maksimaliai ikoniška \\
\hline \multirow{2}{*}{ Dgs. ing. } & kas-õm & adityvinis & maksimaliai ikoniška \\
\hline & de..ž-ệm & adityvinis & maksimaliai ikoniška \\
\hline \multirow{2}{*}{ Dgs. viet. } & kas-ósa & adityvinis & maksimaliai ikoniška \\
\hline & dẹ.žzẹ́sa & adityvinis & maksimaliai ikoniška \\
\hline \multirow{2}{*}{ Dgs. iliat. } & kas-õsna & adityvinis & maksimaliai ikoniška \\
\hline & de.ž- ễsna & adityvinis & maksimaliai ikoniška \\
\hline
\end{tabular}




\begin{tabular}{|c|c|c|c|}
\hline \multicolumn{4}{|l|}{1 lentelès tęsinys } \\
\hline \multicolumn{4}{|c|}{ Mišrusis linksniavimas $\left(\boldsymbol{i}_{m}, \boldsymbol{i}_{f}, \boldsymbol{C}_{m}, \boldsymbol{C}_{f}\right.$ kamienai) } \\
\hline Linksnis & Fleksinè forma & Formos tipas & Ikoniškumo laipsnis \\
\hline \multicolumn{4}{|c|}{ Pamatinè forma $d \alpha \hat{n} c-i \grave{s}$, pir̂c-ìs } \\
\hline \multirow{2}{*}{ Vns. kilm. } & $d \alpha \tilde{\tilde{n}} \hat{c}-o$ & subtrakcinis & kontraikoniška \\
\hline & pirc-iẽs & adityvinis & maksimaliai ikoniška \\
\hline \multirow{2}{*}{ Vns. naud. } & $d \alpha \tilde{n} \hat{c}-u$ & subtrakcinis & kontraikoniška \\
\hline & $p i \tilde{\tilde{r}} c-e i$ & modifikacinis & minimaliai ikoniška \\
\hline \multirow{2}{*}{ Vns. gal. } & $d \alpha \tilde{\hat{n}} \hat{c}-i$ & subtrakcinis & kontraikoniška \\
\hline & pi $\tilde{r} c-i$ & subtrakcinis & kontraikoniška \\
\hline \multirow{2}{*}{ Vns. ing. } & dânc-ù & subtrakcinis & kontraikoniška \\
\hline & pirc-iñ & modifikacinis & minimaliai ikoniška \\
\hline \multirow{2}{*}{ Vns. viet. } & $d \alpha \hat{n} c-\tilde{i}$ & subtrakcinis & kontraikoniška \\
\hline & $\operatorname{pir} c-\tilde{i}$ & subtrakcinis & kontraikoniška \\
\hline \multirow{2}{*}{ Vns. iliat. } & $d \alpha \hat{n} c-i \tilde{n}$ & modifikacinis & minimaliai ikoniška \\
\hline & pirc-iñ & modifikacinis & minimaliai ikoniška \\
\hline \multirow{2}{*}{ Dgs. vard. } & $d \alpha \tilde{\tilde{n}} c-i . s$ & modifikuotas adityvinis & $\begin{array}{c}\text { mažiau negu } \\
\text { maksimaliai ikoniška }\end{array}$ \\
\hline & pi $\tilde{\tilde{r}} c-i . s$ & modifikuotas adityvinis & $\begin{array}{c}\text { mažiau negu } \\
\text { maksimaliai ikoniška }\end{array}$ \\
\hline \multirow{2}{*}{ Dgs. kilm. } & $d \alpha \hat{n} t-\tilde{u}$ & subtrakcinis & kontraikoniška \\
\hline & $\operatorname{pir} \hat{c}-\tilde{u}$ & subtrakcinis & kontraikoniška \\
\hline \multirow{2}{*}{ Dgs. naud. } & $d \alpha \hat{n} c-i \tilde{m}$ & modifikacinis & minimaliai ikoniška \\
\hline & pir̂c-iñ & modifikacinis & minimaliai ikoniška \\
\hline \multirow{2}{*}{ Dgs. gal. } & $d \alpha \hat{n} c-\grave{i} s$ & nekintamasis & neikoniška \\
\hline & pirc-ìs & nekintamasis & neikoniška \\
\hline \multirow{2}{*}{ Dgs. įng. } & $d \alpha \hat{n} c-i \tilde{m}$ & modifikacinis & minimaliai ikoniška \\
\hline & pir̂c-iñ & modifikacinis & minimaliai ikoniška \\
\hline \multirow{2}{*}{ Dgs. viet. } & $d \alpha \hat{n} c-\dot{i} s a$ & adityvinis & maksimaliai ikoniška \\
\hline & pirc-ís $s a$ & adityvinis & maksimaliai ikoniška \\
\hline \multirow{2}{*}{ Dgs. iliat. } & dañc- $\tilde{i}$ sna & adityvinis & maksimaliai ikoniška \\
\hline & pir̂- $\tilde{i}$ sna & adityvinis & maksimaliai ikoniška \\
\hline \multicolumn{4}{|c|}{ Pamatinè forma $a k m-u \tilde{o}$, ses-uõ } \\
\hline \multirow{2}{*}{ Vns. kilm. } & älkmeñ-o. & subtrakcinis & kontraikoniška \\
\hline & $\operatorname{seser}-s$ & subtrakcinis & kontraikoniška \\
\hline \multirow{2}{*}{ Vns. naud. } & $\tilde{a} \cdot k m e \hat{n}-u$ & subtrakcinis & kontraikoniška \\
\hline & sǽ.ser-ei & modifikacinis & minimaliai ikoniška \\
\hline \multirow{2}{*}{ Vns. gal. } & $\tilde{a} \cdot k m e n-i$. & subtrakcinis & kontraikoniška \\
\hline & sǽ.ser-i. & subtrakcinis & kontraikoniška \\
\hline \multirow{2}{*}{ Vns. ing. } & $\tilde{a} \cdot k m e \hat{n}-u$ & subtrakcinis & kontraikoniška \\
\hline & seser-iñ & modifikacinis & minimaliai ikoniška \\
\hline
\end{tabular}




\begin{tabular}{|c|c|c|c|}
\hline \multicolumn{4}{|l|}{1 lentelès tęsinys } \\
\hline \multicolumn{4}{|c|}{ Mišrusis linksniavimas $\left(i_{m}, i_{f}, C_{m}, C_{f}\right.$ kamienai) } \\
\hline Linksnis & Fleksinè forma & Formos tipas & Ikoniškumo laipsnis \\
\hline \multirow{2}{*}{ Vns. viet. } & akmen- $\tilde{i}$ & subtrakcinis & kontraikoniška \\
\hline & $* * \operatorname{seser}-\tilde{i}$ & subtrakcinis & kontraikoniška \\
\hline \multirow[t]{2}{*}{ Vns. iliat. } & akmen-iñ & modifikacinis & minimaliai ikoniška \\
\hline & $* *$ seser-iñ & modifikacinis & minimaliai ikoniška \\
\hline \multirow[t]{2}{*}{ Dgs. vard. } & $\tilde{a} \cdot k m e n-i . s$ & modifikacinis & minimaliai ikoniška \\
\hline & sǽ.ser-i.s & modifikacinis & minimaliai ikoniška \\
\hline \multirow[t]{2}{*}{ Dgs. kilm. } & akmen- $\tilde{u}$ & subtrakcinis & kontraikoniška \\
\hline & seser- $\tilde{u}$ & subtrakcinis & kontraikoniška \\
\hline \multirow[t]{2}{*}{ Dgs. naud. } & 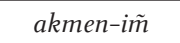 & modifikacinis & minimaliai ikoniška \\
\hline & seser-iñ & modifikacinis & minimaliai ikoniška \\
\hline \multirow[t]{2}{*}{ Dgs. gal. } & a.kmen-is & modifikacinis & minimaliai ikoniška \\
\hline & sǽ.ser-is & modifikacinis & minimaliai ikoniška \\
\hline \multirow[t]{2}{*}{ Dgs. ing. } & 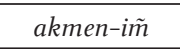 & modifikacinis & minimaliai ikoniška \\
\hline & seser-iñ & modifikacinis & minimaliai ikoniška \\
\hline \multirow[t]{2}{*}{ Dgs. viet. } & akmen-í'sa & adityvinis & maksimaliai ikoniška \\
\hline & $* *$ seser-ísa & adityvinis & maksimaliai ikoniška \\
\hline \multirow[t]{2}{*}{ Dgs. iliat. } & akmen-ĩsna & adityvinis & maksimaliai ikoniška \\
\hline & **seser- $\tilde{i}$ sna & adityvinis & maksimaliai ikoniška \\
\hline
\end{tabular}

Laipsniais ịvertintas Varėnos šnektos (16) formų ikoniškumas rodo, kad ryškiau koduojamos daugiskaitos (jos formų konstrukciškai yra „daugiau“), o ne vienaskaitos formos, t. y. daugiskaitos kodavimas šnektoje dažnesnis. Tai, A. Rosino [14, 39] teigimu (17), būdinga natūralioms kalboms.

Palyginus Varėnos šnektos daiktavardžių vienaskaitos ir daugiskaitos formų konstrukcinio ikoniškumo kodavimą matyti, kad vyriškojo linksniavimo $a$, $i a_{1}$ kamienų daugiskaitos inagininko, vietininko ir iliatyvo formos yra maksimaliai ikoniškos, vadinasi, maksimaliai natūralios, taigi ir konstrukciškai produktyvios. $a$, $\underset{\text { }}{ } a_{1}$ kamienų vienaskaitos įnagininko, vietininko ir iliatyvo formos šnektoje yra kontraikoniškos arba minimaliai ikoniškos.

$a$, $\underset{c}{i} a_{1}$ kamienų paradigmoje vyrauja kontraikoniškos formos, kiek mažiau yra minimaliai ikoniškų formų, t. y. vienaskaitos iliatyvas, daugiskaitos vardininkas, naudininkas, galininkas.

Vyriškojo linksniavimo $\underset{\sim}{i} a_{2}, u$, $\underset{\sim}{i} u$ kamienų paradigmose, be daugiskaitos įnagininko, vietininko ir iliatyvo, maksimaliai ikoniškos dar ir $u$, $\underset{n}{i} u$ kamienų vienaskaitos kilmininko formos; $i a_{2}$ kamieno vienaskaitos kilmininko forma yra kontraikoniška. $u$, $i u$ kamienų paradigmose, skirtingai nei $a, i a_{1}$ kamienų, yra neikoniškų daugiskaitos galininko formų. Atkreiptinas dèmesys ị tai, kad, nors $\underset{n}{i} a_{2}$ ir $u$, $\underset{n}{i} u$ kamienai yra gana panašūs (panašumo indeksas atitinkamai 7,9 ir 9,1), jų formų kodavimas ne visada yra vienodas - be skirtingo vienaskaitos kilmininko formų kodavimo, nevienodas vienaskaitos įnagininko ( $\mathrm{ia}_{2}$ ir $\underset{\mathrm{i}}{\mathrm{C}} \mathrm{u}$

(16) Plg. Joniškio [5, 95-102] ir šiaurinių širvintiškių šnektų duomenis [12, 58-60].

(17) Autorius remiasi W. Mayerthaleriu (1981); plg. [11, 19]. 
kamienų formos kontraikoniškos, $u$ kamieno forma - minimaliai ikoniška), vienaskaitos vietininko ( $i a_{2}$ kamieno forma kontraikoniška, $u$, $\underset{n}{i} u$ kamienų - minimaliai ikoniška) ir daugiskaitos galininko ( $i a_{2}$ kamieno forma minimaliai ikoniška, $u$, $\underset{n}{ } u$ kamienų - neikoniškos) kodavimas.

Moteriškojo linksniavimo $\bar{a}, \bar{e}$ kamienų paradigmose vyrauja maksimaliai ikoniškos formos. Maksimaliai koduojamos vienaskaitos ir daugiskaitos naudininko, vietininko ir iliatyvo formos; daugiskaitos galininko ir innagininko formos taip pat yra maksimaliai ikoniškos, tačiau šių linksnių vienaskaitos kodavimas yra minimaliai ikoniškas. Maksimaliai ikoniškos ir $\bar{a}, \bar{e}$ kamienų daugiskaitos vardininko formos.

Mišriojo linksniavimo $i_{m}, i_{f}, C_{m}, C_{f}$ kamienų maksimaliai ikoniškos yra daugiskaitos vietininko ir iliatyvo formos. Ju atitinkamos vienaskaitos formos yra kontraikoniškos arba minimaliai ikoniškos. $i_{f}$ kamieno maksimaliai ikoniška dar ir vienaskaitos kilmininko forma, mažiau negu maksimaliai ikoniškai koduojamos daugiskaitos vardininko formos.

Kaip matyti, visų kamienų paradigmose maksimaliai ikoniškai koduojamos daugiskaitos vietininko ir daugiskaitos iliatyvo formos, vadinasi, šių linksnių formos, taigi ir morfologinis procesas, visada yra maksimaliai natūralūs. Ir, nors nèra iki galo ištirta, kaip iš natūralumo formuojasi produktyvumas, tačiau atrodo, kad natūralumas didina produktyvumą $[1,59](18)$. Natūralias formas šnektos vartotojai lengviau pasidaro ir greičiau supranta [plg. 1, 59].

Norint nustatyti morfologinio proceso žymètumo laipsnị, reikètų atkreipti dèmesị $\mathfrak{i}$ jo semantinị ir simbolizavimo žymètumus [14, 40]. Apibendrinus 1-os lentelès duomenis, galima teigti, kad maksimaliai paprastas ir maksimaliai nežymètas (max sim) yra segmentinis adityvinis morfologinis procesas, t. y. visos maksimaliai ikoniškos formos. Kiek mažiau natūralus ir paprastas, taigi ir nežymètas $(\mathrm{sim})$, yra modifikuotas adityvinis procesas, t. y. visos mažiau negu maksimaliai ikoniškos formos. Modifikuotas morfologinis procesas, t. y. minimaliai ikoniškos formos, šnektoje yra žymètas (sim), o subtrakcinis morfologinis procesas, t. y. kontraikoniškos formos, yra maksimaliai žymètas ( $\max$ sim) [plg. 14, 40].

Morfologinis procesas maksimaliai natūralus tada, kai jis optimaliai koduojamas kategorijoje $[1,59](18)$, o „simbolizavimas yra optimalus resp. maksimaliai paprastas tik tada, kai jis yra konstrukciškai ikoniškas, vienodas ir skaidrus“ $[14,40](20)$. Be to, nuo morfologinio proceso skaidrumo, ikoniškumo ir vienodumo priklauso formos produktyvumo laipsnis $[14,40]$.

Varėnos šnektos skaičiaus ir linksnio kategorijų simbolizavimas, kaip matyti 1-oje lenteleje, nèra vienodas, optimalus ir skaidrus - yra neikoniškų fleksinių klasių išvestinių formų. Be to, tiriamojoje šnektoje esama sinkretinių, t. y. kelias funkcijas atliekančių, formų.

\section{VERTIKALUSIS (FORMŲ) SINKRETIZMAS}

Varėnos šnektoje linksnių sinkretizmas, arba suvienodejimas, pastebimas ne tik vienoje konkrečioje paradigmoje (vertikaliai), bet ir keliose skirtingose paradigmose (horizontaliai).

(18) "The presupposition here is that there are universal patterns of naturalness for specific categories (e. g. $\langle\ldots\rangle$ that the singular is likely to be unmarked with relation to the plural and the dual in nouns, and so on). A maximally natural morphological process must not conflict with these principles of universal markedness, and so must not add affixes for the singular of nouns, for instance" $[1,59]$. 
Linksnių formų sinkretizmas, atsiradęs, A. Rosino [14, 42] teigimu, dèl žodžio galo fonologinių pakitimų ir dèl morfologijos raidos tendencijų, suprantamas kaip funkcinis skirtingų morfemų sujungimas [plg.: 9, 355; 10, 638; 2, 34].

Varènos šnektos daiktavardžių sinkretinès linksnių formos pateikiamos 2-oje lentelèje (19).

2 lentelè. Sinkretinès linksnių formos

\begin{tabular}{|c|c|c|}
\hline Fleksinè klasè & Skaičius & Sinkretinės formos \\
\hline \multirow{2}{*}{$a$} & Vns. & - \\
\hline & Dgs. & - \\
\hline \multirow{2}{*}{$\underset{\sim}{i} a_{1}, i a_{2}$} & Vns. & V. $\neq$ K. $\neq$ N. $\neq$ G. $\neq$ ln. $\neq$ Vt. $=$ Š. $\neq \neq I$. \\
\hline & Dgs. & V. $=$ S. $\neq \neq$ K. $\neq$ N. $\neq$ G. $\neq l$ n. $\neq$ Vt. $\neq$ II. \\
\hline \multirow{2}{*}{$\bar{a}, i \bar{a}, \bar{e}, i_{f}, C_{f}$} & Vns. & - \\
\hline & Dgs. & 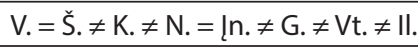 \\
\hline \multirow{2}{*}{$i_{m}$} & Vns. & V. $\neq$ K. $\neq$ N. $=[$ ln. $\neq$ G. $\neq$ Vt. $\neq$ II. $\neq$ Š. \\
\hline & Dgs. & 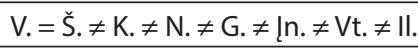 \\
\hline \multirow{2}{*}{$u, i u$} & Vns. & - \\
\hline & Dgs. & V. $=$ Š. $\neq$ K. $\neq$ N. $\neq$ G. $\neq l$ n. $\neq$ Vt. $\neq \neq l l$. \\
\hline \multirow{2}{*}{$C_{m}$} & Vns. & 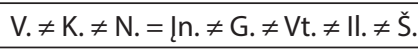 \\
\hline & Dgs. & V. $=$ Š. $\neq$ K. $\neq$ N. $=\left\lfloor\imath\right.$ n. $\neq$ G. $\neq$ Vt. $\neq \| I_{.}$ \\
\hline
\end{tabular}

Kaip matyti iš 2-os lentelès, $a$ kamieno daiktavardžiai neturi nė vienos sinkretinès vienaskaitos ir daugiskaitos formos. $\bar{a}, i \bar{a}, \bar{e}, i_{f}, C_{f}, u, \underline{i} u$ kamienų daiktavardžiai neturi né vienos sinkretinès vienaskaitos formos.

Varènos šnektoje ị vieną formalų linksnị sinkretizuotas:

a) $i a_{1}, i a_{2}$ fleksinių klasių vienaskaitos [VIETININKAS-ŠAUKSMININKAS], plg.: kelí,

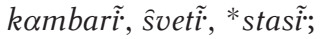

b) $\bar{a}, \underline{i} \bar{a}, \bar{e}, i_{f}, C_{f}, C_{m}$ fleksinių klasių daugiskaitos [NAUDININKAS-ĮNAGININKAS], plg.:

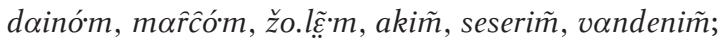

c) $i_{m}, C_{m}$ fleksinių klasių vienaskaitos [NAUDININKAS-İNAGININKAS], plg.: dǽ.beŝu, vándeñu;

d) $\grave{i} a_{1}, i a_{2}, \bar{a}, \underline{i} \bar{a}, \bar{e}, i_{m}, i_{f}, u, \underline{i} u, C_{m}, C_{f}$ fleksiniu klasių daugiskaitos [VARDININKAS-

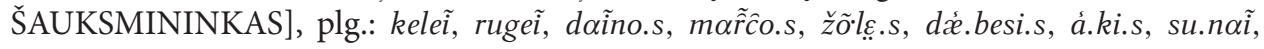
spiecệi, šùni.s, sæx.seri.s.

Akivaizdu, kad sinkretinès linksnių formos vienaskaitos ir daugiskaitos paradigmose pasiskirsto nevienodai [plg. 14, 42], taigi galima skirti du vienaskaitos ir du daugiskaitos tipus.

Varẻnos šnektoje vienaskaitos paradigmų tipai yra šie:

1. Paradigmos su ị vieną formalų linksnị sinkretizuotu vietininku-šauksmininku, t. y. V. $\neq$ K. $\neq$ N. $\neq$ G. $\neq$ In. $\neq$ Vt. $=$ S. $\neq$ Il.; šiam tipui priklauso $i a_{1}, i a_{2}$ fleksinių klasių paradigmos.

2. Paradigmos su ị vieną formalų linksnį sinkretizuotu naudininku-įnagininku, t. y. V. $\neq$ K. $\neq$ N. $=$ In. $\neq$ G. $\neq$ Vt. $\neq$ Il. $\neq$ Š.; šiam tipui priklauso $i_{m}, C_{m}$ fleksinių klasių paradigmos.

(19) Aprašant šnektos fleksinių formų sinkretizmą remiamasi oksitoninio kirčiavimo daiktavardžių paradigmomis, kurios šnektoje yra gerai atstovaujamos. 
Tiriamosios šnektos daiktavardžių formų sinkretizmas dar labiau sumažètų iš linksnių sistemos pašalinus šauksmininką - tuomet būtų tik vienas vienaskaitos paradigmų tipas, t. y. paradigmos su sinkretizuotu naudininku-inagininku, t. y. V. $\neq$ K. $\neq$ N. $=$ In. $\neq$ G. $\neq$ Vt. $\neq$ Il. $\neq$ Š Šiam tipui priklauso $i_{m}, C_{m}$ fleksinių klasių paradigmos. Kaip matyti, i j ji patenka tik mišriojo linksniavimo daiktavardžiai, nepatenka vyriškojo ir moteriškojo linksniavimo daiktavardžiai.

Daugiskaitos paradigmų tipai šnektoje yra tokie:

1. Paradigmos su į vieną formalų linksnị sinkretizuotu vardininku-šauksmininku, t. y. V. $=\check{\mathrm{S}} . \neq \mathrm{K} . \neq \mathrm{N} . \neq \mathrm{G} . \neq$ In. $\neq$ Vt. $\neq$ Il.; šiam tipui priklauso $\underset{\sim}{i} a_{1}, \underset{n}{i} a_{2}, i_{m}$ ir $u$, in $u$ fleksinių klasių paradigmos.

2. Paradigmos su ị vieną formalų linksnị sinkretizuotu vardininku-šauksmininku ir naudininku-įnagininku, t. y. V. $=\breve{\mathrm{S}} . \neq \mathrm{K} . \neq \mathrm{N} .=\mathrm{I}_{\mathrm{n}} . \neq \mathrm{G} . \neq \mathrm{Vt} . \neq \mathrm{Il}$.; šiam tipui priklauso $\bar{a}, \underline{i} \bar{a}$, $\bar{e}, i_{f}, C_{m}, C_{f}$ fleksinių klasių paradigmos.

Iš šnektos linksniavimo sistemos pašalinę šauksmininką, vietoj dviejų daugiskaitos paradigmų tipų turètume vieną su sinkretizuotu naudininku-įnagininku, t. y. V. $\neq \mathrm{K} . \neq \mathrm{N} .=$ In. $\neq \mathrm{G} . \neq$ Vt. $\neq$ Il. Šiam tipui priklausytų $\bar{a}, \underline{i} \bar{a}, \bar{e}, i_{f}, C_{m}, C_{f}$ fleksinių klasių paradigmos.

$i a_{1}, i a_{2}, i_{m}$ ir $u$, in fleksinių klasių paradigmos, be vardininko-šauksmininko, daugiau sinkretinių formų neturi, taigi sinkretizmas nèra būdingas.

Varénos šnektos daiktavardžių formų vertikaliojo sinkretizmo analizė parodè, kad šnektoje fleksinių klasių paradigmos dẻl mažo sinkretinių formų buvimo yra geriau diferencijuotos, taigi ir natūralesnès, palyginti su Joniškio [5, 103-105], šiaurinių širvintiškių [12, 61-69], Šaukènų [13, 59-60] šnektų, latvių bendrinès kalbos [14, 42-44] daiktavardžio formomis.

\section{HORIZONTALUSIS (GALŪNIŲ) SINKRETIZMAS}

Aptarus Varènos šnektos vertikalųji daiktavardžio linksnių formų sinkretizmą, tikslinga pereiti prie horizontaliojo sinkretizmo, t. y. visų kamienų tų pačių linksnių formų galūnių, arba gramatinių morfemų, analizès. Dèl žodžio galo fonologinių pakitimų atsiradusios vienodos daiktavardžių gramatinès morfemos (kaip ir sinkretinès linksnių formos) siejamos su daugiareikšmiškumu, taigi ir mažesniu natūralumu.

Tiriamojoje šnektoje horizontaliai sinkretizuotos šios linksnių formų gramatinès morfemos:

1. /-as/ (/-es/), kurią turi $a$, $i a_{1}$ fleksinių klasių vienaskaitos vardininkas, plg.: ná.m-as, kǽ.l-es.

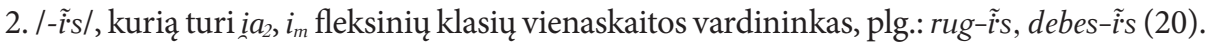

3. /-ùs/, kurią turi $u$, inu fleksinių klasių vienaskaitos vardininkas, plg.: su·n-ùs, spieĉ-ùs.

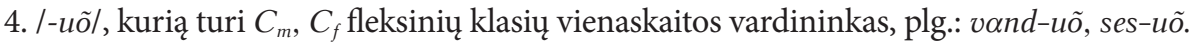

5. /-o./, kurią turi $a, i a_{1}, i a_{2}, i_{m}, C_{m}$ fleksinių klasių vienaskaitos kilmininkas, plg.: ná.m-o., kǽ. l̂-o., rùg-o., dǽ.beŝ-o., vándeñ-o..

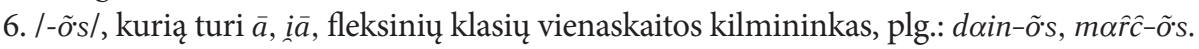

7. /-åús/, kurią turi $u$, inu fleksinių klasių vienaskaitos kilmininkas, plg.: su.n-åús, ŝpiec-åús.

8. /-u/, kurią turi $a, \underline{i} a_{1}, \underline{i} a_{2}, i_{m}, u, \underline{i} u, C_{m}$ fleksinių klasių vienaskaitos naudininkas, plg.:

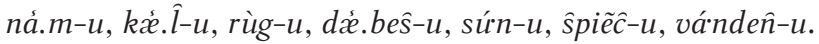

9. /- $\alpha i /$ (/-ei/), kurią turi $\bar{a}, i \bar{a}, \bar{e}, i_{f}, C_{f}$ fleksinių klasių vienaskaitos naudininkas, plg.:

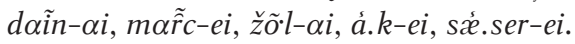

(20) Atkreiptinas dèmesys ị tai, kad, apžvelgiant šnektos horizontalųji sinkretizmą, $i_{m}$ kamieno atstovu imama daiktavardžio forma debes- $\tilde{i}$ 's dèl dažnesnio vartojimo ir platesnio paplitimo. Daiktavardžio formos debesìs, vagìs, dancìs palyginti retos šnektoje. 
10. /-u./, kurią turi $a, i a_{1}, \bar{a}, i \bar{a}, u, i n u$ fleksinių klasių vienaskaitos galininkas, plg.: ná.m-u.,

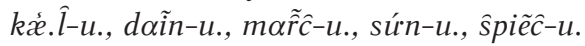

11. /-i./, kurią turi $\underset{i}{i} a_{2}, \bar{e}, i_{m}, i_{f}, C_{m}, C_{f}$ fleksinių klasių vienaskaitos galininkas, plg.: rùg-i., žõ l-bl., dǽ.bes-i., á.k-i., vánden-i., sǽ.ser-i..

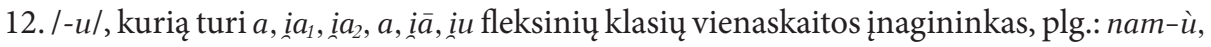

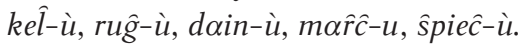

13. /-u/, kurią turi $i_{m}, C_{m}$ fleksinių klasių vienaskaitos įnagininkas, plg.: dǽ.beŝ-u, vánden̂-u.

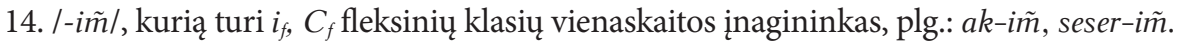

15. / $\tilde{i} /$, , kurią turi $i a_{1}, i a_{2}, i_{m}, i_{f}, C_{m}, C_{f}$ fleksinių klasių vienaskaitos vietininkas, plg.: kel- $\tilde{i}$,

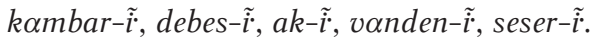

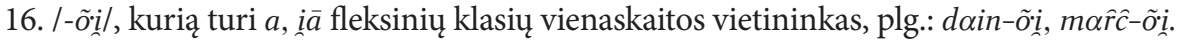

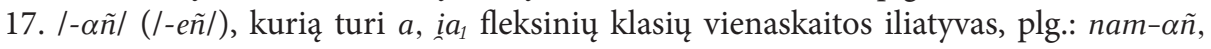
kel-eñ.

18. /-iñn/, kurią turi $i a_{2}, i_{m}, i_{f}, C_{m}, C_{f}$ fleksinių klasių vienaskaitos iliatyvas, plg.: kambar-iñ, debes-iñ, ak-iñ, vanden-iñ, seser-iñ.

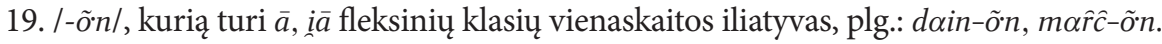

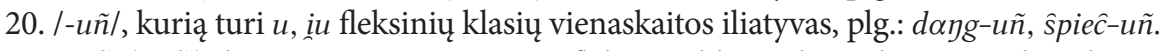

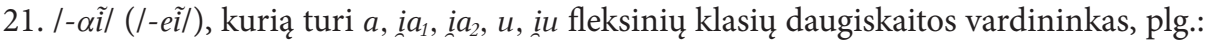

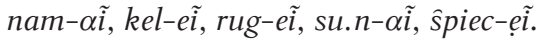

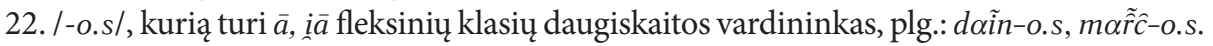

23. /-i.s/, kurią turi $i_{m}, i_{f}, C_{m}, C_{f}$ fleksinių klasių daugiskaitos vardininkas, plg.: dǽ.bes-i.s, á.k-i.s, vánden-i.s, sǽ.ser-i.s.

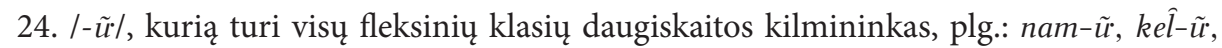

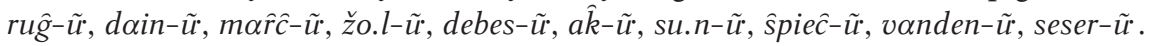

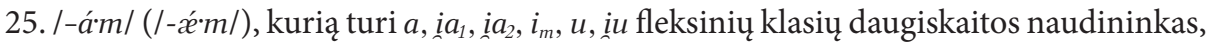
plg.: nam-ám, kel-ǽ'm, rug-ǽ'm, debes-ǽm su.n-ám, ŝpiec-ǽ $m$.

26. /-óm/, kurią turi $\bar{a}$, ina fleksinių klasių daugiskaitos naudininkas, plg.: doin-óm, mar̂́-óm.

27. /-im̃ /, kurią turi $i_{f}, C_{m}, C_{f}$ fleksinių klasių daugiskaitos naudininkas, plg.: $a k-i \tilde{m}$, vanden-im, seser-im.

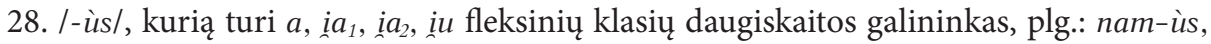
kel-ùs, ruĝ-ùs, spieĉ-ùs.

29. /-às/ (/-ès/), kurią turi $\bar{a}, i \grave{n}, \bar{e}$ fleksinių klasių daugiskaitos galininkas, plg.: dain-às, mârc-ès, žo.l-às.

30. /-is/, kurią turi $i_{m}, C_{m}, C_{f}$ fleksinių klasių daugiskaitos galininkas, plg.: dǽ.bes-is, vánden-is, sǽ.ser-is.

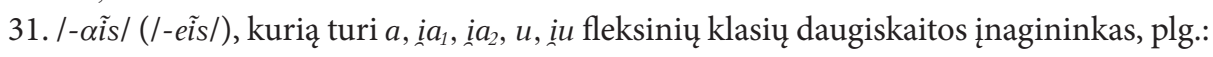

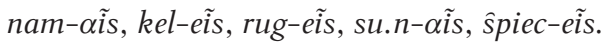

32. /-õm/, kurią turi $\bar{a}$, ịa fleksinių klasių daugiskaitos įnagininkas, plg.: dain-õm, $m \alpha \hat{r} \hat{c}-\tilde{o} m$.

33. /-iĩ /, kurią turi $i_{m}, i_{f}, C_{m}, C_{f}$ fleksinių klasių daugiskaitos įnagininkas, plg.: debes-im,

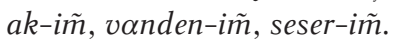

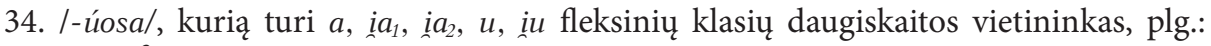

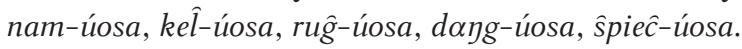


35. /-ósa/, kurią turi $a$, ina fleksinių klasių daugiskaitos vietininkas, plg.: dain-ó'sa, mar̂́-ósa.

36. /-ísa/, kurią turi $i_{m}, i_{f}, C_{m}, C_{f}$ fleksinių klasių daugiskaitos vietininkas, plg.: debes-ísa, $a k-\dot{i}$ 'sa, vanden-ísa, seser-ísa.

37. /-uõsna/, kurią turi $a, \underset{\sim}{i} a_{1}, i a_{2}, u$, inu fleksinių klasių daugiskaitos iliatyvas, plg.: nam-uõsna, kêे-uõsna, ruĝ-uõsna, dayg-uõsna, ŝpieĉ-uõsna.

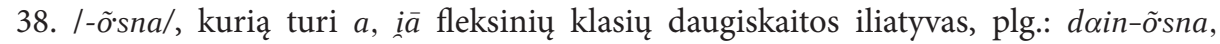

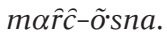

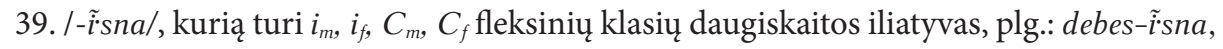

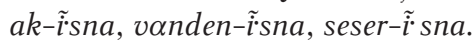

Kaip matyti, Varènos šnektoje tik daugiskaitos kilmininkas turi vieną sinkretinę galūnę /- $\tilde{u} /$, kurią galima vadinti superstabiliu žymikliu [plg. 14, 44] (23). Tokiu žymikliu galètume laikyti ir vienaskaitos naudininko gramatinę morfemą /-u/ resp. /-ai/ (/-ei/).

Visų kamienų daiktavardžio linksnių formų gramatinių morfemų (galūnių) lyginimas rodo, kad tiriamojoje šnektoje visi linksniai (tiek vienaskaitos, tiek daugiskaitos) turi sinkretinių formų. Taigi galima daryti išvadą, kad nepakankamai gerai yra atstovaujami kamienų požymiai. Be to, šnektos horizontalusis linksnių sinkretizmas gerokai didesnis už vertikalųjị, o tai reiškia, kad fleksinès klasès linkusios ne tik suartėti, bet ir supanašèti.

\section{IŠVADOS}

1. Varènos šnektos daiktavardžio fleksinès formos ne visada optimaliai koduojamos kategorijoje, taigi morfologinis procesas nèra maksimaliai natūralus.

2. Vertikalusis (daiktavardžio formų) sinkretizmas parodè, kad šnektoje yra vienas vienaskaitos paradigmos tipas, t. y. paradigmos su ị vieną formalų linksnị sinkretizuotu naudininku-įnagininku, t. y. V. $\neq$ K. $\neq$ N. $=$ In. $\neq$ G. $\neq$ Vt. $\neq \mathrm{Il} . \neq$ S. (šiam tipui priklauso $i_{m}, C_{m}$ fleksinių klasių paradigmos) ir vienas daugiskaitos paradigmos tipas, t. y. paradigmos su sinkretizuotu naudininku-įnagininku, t. y. V. $\neq \mathrm{K} . \neq \mathrm{N} .=$ In. $\neq$ G. $\neq$ Vt. $\neq$ Il. (šiam tipui priklausytų $\bar{a}, i \bar{a}, \bar{e}, i_{f}, C_{m}, C_{f}$ fleksinių klasių paradigmos).

3. Horizontalusis (daiktavardžio formų gramatinių morfemų) sinkretizmas parodè, kad tiriamojoje šnektoje visi linksniai (tiek vienaskaitos, tiek daugiskaitos) turi sinkretinių formų, vadinasi, nepakankamai gerai atstovaujami kamienų požymiai; be to, kaip matyti, šnektos horizontalusis linksnių sinkretizmas gerokai didesnis už vertikalųji, o tai reiškia, kad fleksinès klasès linkusios ne tik suartèti, bet ir supanašèti.

4. Varėnos šnektoje egzistuoja superstabilūs žymikliai. Visi vyriškosios giminès daiktavardžiai turi superstabilų, vadinasi, ir produktyvų, vienaskaitos naudininko žymiklị /-u/, o visi moteriškosios giminès daiktavardžiai turi superstabilų vienaskaitos naudininko žymiklị /-ai/ (/-ei/).

5. Varènos šnektos fleksinių formų analizė parodè, kad ne visas morfologinis procesas (fleksinès formos) yra skaidrus - šnektoje esama neikoniškų ir sinkretinių formų, todèl netikslu būtų šnektos fleksinę sistemą laikyti idealiai natūralia. 


\section{Literatūra}

[1] BAUER, Laurie. Morphological Productivity. Cambridge: University Press, 2003.

[2] CORBETT, Greville G. The canonical approach in typology. Linguistic Diversity and Language Theories. Edited by Z. Frajzyngier, A. Hodges, D. S. Rood. Amsterdam: John Benjamins Publishing, 2005, p. 25-50.

[3] DRESSLER, Wolfgang Ulrich. Interactions between Iconicity and Other Semiotic Parameters in Language. Iconicity in Language. Edited by R. Simone. Amsterdam: John Benjamins Publishing,1995, p. 21-38.

[4] DRESSLER, Wolfgang Ulrich. Naturalness. In: G. E. Booij, Ch. Lehmann, J. Mugdan. Morphologie / Morphology: Ein Internationales Handbuch Zur Flexion Und Wortbildung / An International Handbook on Inflection and Word-Formation 1. Berlin, New York: Walter de Gruyter, 2000, p. 288-296.

[5] KAIKARYTĖ, Aušra. Joniškio šnektos daiktavardžio linksniavimo sistema: daktaro disertacija. Vilnius: Lietuvių kalbos institutas, 2010.

[6] KOEFOED, Geert; VAN MARLE, Jaap. Productivity. In: G. E. Booij, Ch. Lehmann, J. Mugdan. Morphologie / Morphology: Ein Internationales Handbuch Zur Flexion Und Wortbildung/ An International Handbook on Inflection and Word-Formation 1. Berlin, New York: Walter de Gruyter, 2000, p. 303-311. [7] LINM - Leitmotifs in Natural Morphology by Wolfgang U. Dressler, Willi Mayerthaler, Oswald Panagl and Wolfgang Ullrich Wurzel. Edited by W. U. Dressler. Amsterdam, Philadelphia: John Benjamins Publishing Company, 1987.

[8] LKŽe - Lietuvių kalbos žodynas (I-XX, 1941-2002): elektroninis variantas. Redaktorių kolegija: G. Naktinienè (vyr. redaktorè), J. Paulauskas, R. Petrokienė, V. Vitkauskas, J. Zabarskaitė. Vilnius: Lietuvių kalbos institutas, 2005. Prieiga per internetą: $\langle w w w . l k z . l t\rangle$.

[9] LURAGHI, Silvia. Patterns of case syncretism in Indo-European languages. Papers from the 7th International Conference on Historical Linguistics. Edited by A. Giacalone Ramat, O. Carruba, G. Bernini. Amsterdam: John Benjamins Publishing, 1987, p. 355-372.

[10] LURAGHI, Silvia. Synkretismus. In: G. E. Booij, Ch. Lehmann, J. Mugdan. Morphologie / Morphology: Ein Internationales Handbuch Zur Flexion Und Wortbildung / An International Handbook on Inflection and Word-Formation 1. Berlin, New York: Walter de Gruyter, 2000, p. 638-646.

[11] MAYERTHALER, Willi. Morphological Naturalness. Ann Arbor: Karoma, 1988.

[12] MARKEVIČIUS, Aurimas. Šiauriniu širvintiškiu daiktavardžio linksniavimas ir jo istorija: monografija. Vilnius: Vilniaus universiteto leidykla, 2009.

[13] ROSINAS, Albertas. Linksnių sinkretizmo ir analogijos vaidmuo kai kurių linksnių formų raidoje. Baltistica, 2000, t. 35, Nr. 1, p. 59-74.

[14] ROSINAS, Albertas. Latviu kalbos daiktavardžio linksniavimo sistema: sinchronija ir diachronija. Vilnius: Mokslo ir enciklopedijų leidybos institutas, 2005.

[15] SONESSON, Göran. Prolegomena to a general theory of iconicity. Naturalness and Iconicity in Language. Edited by K. Willems, L. de Cuypere. Amsterdam: John Benjamins Publishing, 2008, p. 47-72. [16] TUOMIENĖ, Nijolè. Ramaškoniu šnektos daiktavardis: sociolingvistinis tyrimas. Vilnius: Lietuvių kalbos institutas, 2010.

[17] WURZEL, Wolfgang Ullrich. System-dependent morphological naturalness in inflection. Leitmotifs in Natural Morphology by Wolfgang U. Dressler, Willi Mayerthaler, Oswald Panagl and Wolfgang Ullrich Wurzel. Edited by W. U. Dressler. Amsterdam, Philadelphia: John Benjamins Publishing Company, 1987, p. 59-96.

[18] WURZEL, Wolfgang Ullrich. Inflectional Morphology and Naturalness. Dordrecht: Kluwer, 1989. 
VITALIJA KARACIEJŪTÉ

\section{Naturalness of morphological process (inflectional forms) in Varèna subdialect}

Summary

The naturalness of morphological process (inflectional forms) in Varèna subdialect has not been researched and described so far. The goal of the article is to establish the transparency of the whole morphological process (inflectional forms) of nouns of this subdialect; following the principles of the theory of natural morphology, to evaluate and describe constructional iconicity of case forms, syncretism of noun forms (vertical) and inflections (horizontal). The analysis of inflectional forms in Varena subdialect shows that not the whole morphological process (inflectional forms) is transparent - there are also non-iconic and synchronic forms in Varena subdialect. Therefore, it would be inaccurate to consider the inflectional system of the subdialect as ideally natural.

Key words: Varèna subdialect, natural morphology, constructive iconicity of case forms, vertical (form) syncretism, horizontal (inflectional) syncretism 